DOI 10. 18307/2017. 0315

(C) 2017 by Journal of Lake Sciences

\title{
南京玄武湖浮游细菌群落结构的季节变化及其与环境因子的关系”
}

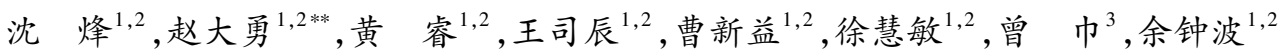 \\ (1: 河海大学水文水资源与水利工程科学国家重点实验室,南京 210098) \\ (2: 河海大学水文水资源学院,南京 210098) \\ (3: 中国科学院南京地理与湖泊研究所湖泊与环境国家重点实验室, 南京 210008)
}

\begin{abstract}
摘 要: 应用 $16 \mathrm{~S} \mathrm{rRNA}$ 基因末端限制性片段长度多态性技术和多元统计方法, 探究了南京玄武湖浮游细菌群落结构的 季节性变化, 并找出了浮游细菌群落组成分布的主要影响因子. 结果表明, 玄武湖 4 个季节中夏季 Invsimpson 指数、Shannon-Wiener 指数和 Pielou 指数最高, 而春季最低. 非度量多维尺度分析结果显示浮游细菌群落结构存在着明显的季节性 变化. Mantel 检验、典范对应分析、变量分割分析表明影响玄武湖细菌群落结构最显著的环境因子为温度,其次为 $\mathrm{pH}$. 营 养盐浓度对玄武湖细菌群落结构的影响不显著. 总的来说, 本研究将有助于更好地理解富营养化水体中的浮游细菌群落 组成的季节变化规律.
\end{abstract}

关键词: 浮游细菌;末端限制性片段长度多态性技术;多元统计;玄武湖

\section{Seasonal variation of bacterioplankton community structure in Xuanwu Lake ( Nanjing) and its relationship with environmental factors}

SHEN Feng ${ }^{1,2}$, ZHAO Dayong ${ }^{1,2 * *}$, HUANG Rui ${ }^{1,2}$, WANG Sichen ${ }^{1,2}$, CAO Xinyi ${ }^{1,2}$, XU Huimin ${ }^{1,2}$, ZENG $\mathrm{Jin}^{3} \&$ YU Zhongbo ${ }^{1,2}$

(1: State Key Laboratory of Hydrology-Water Resources and Hydraulic Engineering, Hohai University, Nanjing 210098, P.R. China)

(2: College of Hydrology and Water Resources, Hohai University, Nanjing 210098, P.R.China)

(3: State Key Laboratory of Lake Science and Environment, Nanjing Institute of Geography and Limnology, Chinese Academy of Sciences, Nanjing 210008, P.R.China)

\begin{abstract}
To explore the seasonal variations of bacterioplankton community structure in Xuanwu Lake and identify the main factors affecting bacterioplankton community composition, the bacterial $16 \mathrm{~S}$ rRNA terminal restriction fragment length polymorphism technology and multivariate statistical methods were applied. The results show that the Invsimpson, Shannon-Wiener and Pielou indexes were the highest in summer, and the lowest in spring. Nonmetric multidimensional scaling analysis showed that bacterioplankton community structure exhibited a seasonal pattern. Mantel test, canonical correlation analysis and variation partitioning analysis show that the most significant environmental factor on the bacterioplankton community structure was temperature, and followed factor was $\mathrm{pH}$. The influence of nutrient concentration was not significant. Overall, this study will be helpful for better understanding of the bacterioplankton community composition in eutrophic lakes.
\end{abstract}

Keywords: Bacterioplankton; terminal restriction fragment length polymorphism technology; multivariate analysis; Xuanwu Lake

南京玄武湖是典型的富营养化城市湖泊, 早在 1980s 后期已经处于严重富营养化状态. 近年来通过底泥

* 国家自然科学基金项目 (41371098,41571108)、水文水资源与水利工程科学国家重点实验室专项研究经费项目 (20145027312，20155019012)、中央高校基本科研业务费项目(2015B14214) 和湖泊与环境国家重点实验室开放基 金项目 (2014SKL010) 联合资助. 2016-03-23 收稿; 2016-07-13 收修改稿. 沈烽(1992 ), 男, 硕士研究生;Email:472779237@qq.com.

** 通信作者;E-mail: dyzhao@ hhu.edu.cn. 
疏浚、截污等方式水质有了明显的改善. 已经有不少工作研究了玄武湖重金属污染 ${ }^{[1]}$ 以及浮游植物 ${ }^{[2]}$ 、浮游 动物的变化 ${ }^{[3]}$ 等,但是对于玄武湖浮游细菌的研究还比较少.

浮游细菌是一种有着极高遗传多样性的生物, 也是湖泊淡水生态系统的重要组成部分, 其在生物化学 地球循环过程中扮演着重要的角色 ${ }^{[4-5]}$. 在城市地区, 由于人类生产生活排放的大量污染物进人湖泊, 改变 了湖泊原有的营养负荷, 使得耐污染的细菌大量繁殖. 对于像玄武湖这样的处于退化状态的水生态系统, 大 型水生生物极少, 生物多样性极低, 以这些生物作为生态系统的表征指标, 无法为生态系统健康的评价提供 足够的信息 ${ }^{[6]}$. 浮游细菌个体结构简单, 对环境变化敏感, 通过对外部环境变化的灵敏响应, 其多样性和群 落组成能真实反映水环境质量的状况 ${ }^{[7]}$, 也可作为水生生态系统健康状况评估的指标 ${ }^{[8-9]}$.

Zeng 等 ${ }^{[10]}$ 已经对玄武湖浮游细菌的空间分布差异做了研究,但是目前尚未发现对玄武湖浮游细菌群 落时间变化的研究. 刘兰英等 ${ }^{[11]}$ 通过研究福州左海的浮游细菌群落, 发现季节变化是决定浮游细菌群落结 构的重要因素. 季节变化会导致湖泊水体温度、pH 等环境因子的变化, 同时改变浮游植物光合作用, 导致水 体中有机物含量发生变化 ${ }^{[12]}$. 在城市水体人类活动输人的营养物质也可能对水体浮游细菌产生重要的影 响 $^{[13]}$. 但是, 不同环境因子对玄武湖浮游细菌群落变化影响的贡献大小目前尚不清楚. 因此, 有必要研究玄 武湖浮游细菌群落结构的季节变化,并揭示导致这种变化的主要环境因子.

1997 年, Liu 等 ${ }^{[14]}$ 首先应用末端限制性片段长度多态性 ( T-RFLP) 技术研究微生物的多样性, 与其他指 纹图谱技术相比, T-RFLP 具有以下优点: (1) 能够迅速产生大量重复、精确的数据 ${ }^{[15]} ;$; (2) 数据的输出形式 允许对大量信息的快速分析; (3) 根据末端限制性片段 ( T-RFs) 的长度与现有数据库进行对比, 有可能直接 鉴定群落图谱中的单个菌种 ${ }^{[16]}$. 近年来 T-RFLP 技术已被广泛应用于土壤 ${ }^{[17-18]}$ 、湖泊沉积物 ${ }^{[19]}$ 、淡水水 体 ${ }^{[20]}$ 等生境中微生物群落的研究.

本文应用 T-RFLP 技术, 对玄武湖不同季节水体中浮游细菌群落组成进行研究, 探讨浮游细菌群落组成 的季节变化, 进而探究浮游细菌群落演替机制. 同时, 通过多种多元统计方法研究浮游细菌群落组成与环境 因子的关系, 找出影响玄武湖浮游细菌群落组成变化的关键环境因子, 相关结果可为玄武湖富营养化水体 的生态修复提供参考.

\section{1 材料与方法}

\section{1 样品采集与准备}

2011 年 1 月至 2012 年 1 月, 分 4 个季节在南京市玄武湖采 集水体样品. 在玄武湖的北湖、东南湖和西南湖 3 个湖区各设置 $2 \sim 3$ 个采样点 (图 1). 最终, 春、夏、秋、冬 4 个季节的实际样品 数分别为 $6 、 8 、 9 、 9$ 个. 每次采样用采水器采集水面以下 $0.5 \mathrm{~m}$ 处 的水样 $1000 \mathrm{ml}$, 分装在经过灭菌处理的蓝色玻璃瓶中, 并现场 测定水温 $(\mathrm{T})$ 及 $\mathrm{pH}$. 采集的水样立即密封避光保存在保温箱中, 并尽快运回实验室分析.

\section{2 水体理化指标分析}

水体 $\mathrm{pH}$ 、温度分别应用便携式 $\mathrm{pH}$ 计 (PHB-4, 上海雷磁) 和

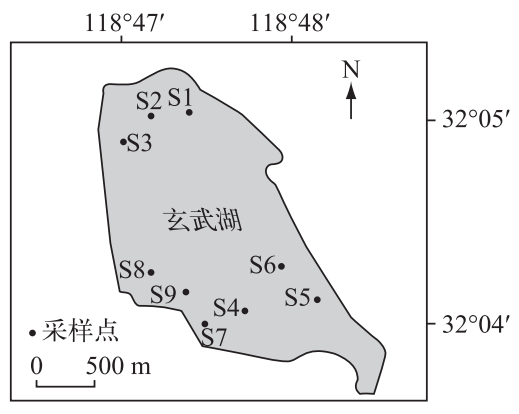

图 1 玄武湖采样点分布

Fig.1 Distribution of sampling sites in Xuanwu Lake 玻璃温度计在现场测定. 未过滤水样经碱性过硫酸钾消解之后, 测定总磷 $(\mathrm{TP})$ 、总氮 $(\mathrm{TN})$ 浓度. 其余水样经 $0.22 \mu \mathrm{m}$ 滤膜过滤, 滤液通过流动注射仪 (San++, SKALAR, Netherlands $)$ 测定铵态氮 $\left(\mathrm{NH}_{4}^{+}-\mathrm{N}\right)$ 、硝态氮 $\left(\mathrm{NO}_{3}^{-}-\mathrm{N}\right)$ 和亚硝态氮 $\left(\mathrm{NO}_{2}^{-}-\mathrm{N}\right)$ 浓度.

\subsection{T-RFLP 分析}

取上述水样通过 $0.22 \mu \mathrm{m}$ 滤膜过滤, 采用 Zeng 等 ${ }^{[10]}$ DNA 提取方法进行 DNA 提取. PCR 扩增反应采用 细菌通用引物对 27F ( $5^{\prime}$-AGAGTTTGATCCTGGCTCAG-3') 和 926R ( $5^{\prime}$-CCGTCAATTCCTTTGAGTTT-3' $)$. 前者 $5^{\prime}$ 端采用 Cy5-N-差基琥珀酰亚胺酯苂光标记, PCR 反应体系和循环条件参照 Zeng 等 ${ }^{[21]}$ 的方法进行. 扩增体 系为 $50 \mu \mathrm{l}$, 包含 $5 \times \mathrm{PCR}$ buffer $10 \mu \mathrm{l} 、 0.25 \mathrm{mmol} / \mathrm{L}$ dNTP、 $2.5 \mathrm{mmol} / \mathrm{L}$ 镁离子、 $0.2 \mathrm{mmol} / \mathrm{L}$ 上下游引物、10 $\mathrm{ng}$ DNA 模板和 $2 \mathrm{U}$ 的 Taq 酶, 再加蒸馏水至 $50 \mu \mathrm{l}$. 扩增程序为 $3 \mathrm{~min} 95^{\circ} \mathrm{C}$ 的预变性, $1 \mathrm{~min} 94^{\circ} \mathrm{C}$ 变性, $1 \mathrm{~min}$ 
$55^{\circ} \mathrm{C}$ 退火, $1 \min 72^{\circ} \mathrm{C}$ 延伸,循环 30 次,最后进行 $7 \min 72^{\circ} \mathrm{C}$ 的延伸, $4^{\circ} \mathrm{C}$ 保存. $\mathrm{PCR}$ 扩增产物采用 $2 \%$ 琼脂糖 凝胶电泳检测.

用绿豆酶 $30^{\circ} \mathrm{C}$ 消化 PCR 产物 $30 \mathrm{~min}$. 用 PCR 产物纯化试剂盒( 爱思进生物技术 (杭州) 有限公司) 纯化 消化后的产物. 然后, 用限制性核酸内切酶 Hha I ( Takara, Otsu, Japan) $37^{\circ} \mathrm{C}$ 消化 $3 \mathrm{~h}$, 之后使用 CEQ8000 (BeckmanCoulter, Fullerton, CA, USA) 核酸片段分析仪对酶切产物进行 T-RFLP 分析. 分析中只考虑长度介 于 $60 \sim 600 \mathrm{bp}$ (bp 表示该片段所具有的碱基数,下同) 以及相对丰度超过 $1 \%$ 的片段的末端限制性片段,即 T-RFs. 按照 T-RFs 占各个样品的丰度百分比标准化, 再分别计算每个样品细菌群落的 Invsimpson 指数、 Shannon-Wiener 指数 $\left(H^{\prime}\right)$ 和 Pielou 指数 $(J)$, 用它们反映水体中浮游细菌的多样性和均匀度. 计算公式 如下:

$$
\begin{gathered}
\text { Invsimpson }=1 / \sum_{i=1}^{n}\left(P_{i}\right)^{2} \\
H^{\prime}=-\sum_{i=1}^{n} P_{i} \cdot \ln P_{i} \\
J=H^{\prime} / \ln S
\end{gathered}
$$

式中, $P_{i}$ 为峰面积占总面积的比例, 即 T-RFs 的相对丰度; $S$ 为 T-RF 数.

对每个季节的多样性指数两两做 $t$ 检验, 若 $P<0.05$ 则认为这两个季节的多样性指数有显著差异, 在图 中用不同的小写字母区分.

\section{4 多元统计分析}

非度量多维尺度分析 (nonmetric multidimensional scaling, NMDS) 用于判定不同样品间细菌群落结构的 差异性; 典范对应分析 (canonical correlation analysis, CCA) 用于研究环境因子对浮游细菌群落结构的影响; Mantel 及偏 Mantel 检验用于探究环境差异与群落结构差异的相关性; 基于冗余分析 ( redundancy analysis, RDA) 的变量分割分析 (variation partitioning analysis, VPA) 用于研究不同环境因子对群落差异的贡献大小. 所有的统计分析方法都应用 R 语言软件 (The R Programming Language, version 3.2.3) 中的 Vegan 程序包 完成.

\section{2 结果}

\section{1 玄武湖水质参数}

玄武湖氮、磷浓度在 4 个季节都已经达到了“中一富” 级富营养化水平 ( Thomas 标准 ${ }^{[22]}$ 中-富级: 无机氮 介于 $0.5 \sim 1.5 \mathrm{mg} / \mathrm{L}$; TP 介于 $0.03 \sim 0.10 \mathrm{mg} / \mathrm{L}$ ), 大部分都达到了 “富” 级水平 ( Thomas 标准富级: 无机氮 $>1.5$ $\mathrm{mg} / \mathrm{L} ; \mathrm{TP}>0.1 \mathrm{mg} / \mathrm{L})$. 在秋、冬季 $\mathrm{TN}$ 浓度有着明显的提高, 平均浓度分别达到 2.321 和 $3.038 \mathrm{mg} / \mathrm{L}$ (表 1 ).

表 1 玄武湖水体物理化学指标

Tab.1 Physico-chemical parameters of Xuanwu Lake

\begin{tabular}{ccccccc}
\hline 季节 & $\mathrm{pH}$ & $\mathrm{TP} /(\mathrm{mg} / \mathrm{L})$ & $\mathrm{TN} /(\mathrm{mg} / \mathrm{L})$ & $\mathrm{NH}_{4}^{+}-\mathrm{N} /(\mathrm{mg} / \mathrm{L})$ & $\mathrm{NO}_{3}^{-}-\mathrm{N} /(\mathrm{mg} / \mathrm{L})$ & $\mathrm{NO}-\mathrm{N} /(\mathrm{mg} / \mathrm{L})$ \\
\hline 春季 & $9.16 \pm 0.18$ & $0.220 \pm 0.044$ & $1.174 \pm 0.344$ & $0.229 \pm 0.191$ & $0.566 \pm 0.254$ & $0.055 \pm 0.026$ \\
夏季 & $8.84 \pm 0.28$ & $0.125 \pm 0.025$ & $1.540 \pm 0.388$ & $0.168 \pm 0.102$ & $0.748 \pm 0.271$ & $0.078 \pm 0.031$ \\
秋季 & $8.00 \pm 0.23$ & $0.129 \pm 0.055$ & $2.321 \pm 0.821$ & $0.712 \pm 0.551$ & $0.990 \pm 0.229$ & $0.060 \pm 0.020$ \\
冬季 & $8.21 \pm 0.26$ & $0.095 \pm 0.024$ & $3.038 \pm 0.814$ & $2.071 \pm 1.031$ & $0.929 \pm 0.202$ & $0.095 \pm 0.034$ \\
\hline
\end{tabular}

\subsection{Alpha 多样性指数分析}

根据 T-RFLP 图谱中 T-RF 数和丰度, 分别计算各样品细菌的多样性指数. Invsimpson 指数表明夏季玄 武湖细菌群落的多样性要显著高于春季和冬季, Shannon-Wiener 指数也表明夏季的细菌群落多样性相对要 比其他季节高. 此外, 从 Pielou 指数看出夏季细菌群落中物种分布较为均匀. Invsimpson 和 Shannon-Wiener 指数都表明玄武湖在春季细菌群落的多样性最低, 并显著低于其他季节 $(P<0.05)$ (图 2).

\section{3 不同季节浮游细菌群落结构差异}

为了探究不同季节玄武湖浮游细菌群落结构的可能差异, 计算了样品间 T-RFs 的差异性 (Bray-Curtis 距 

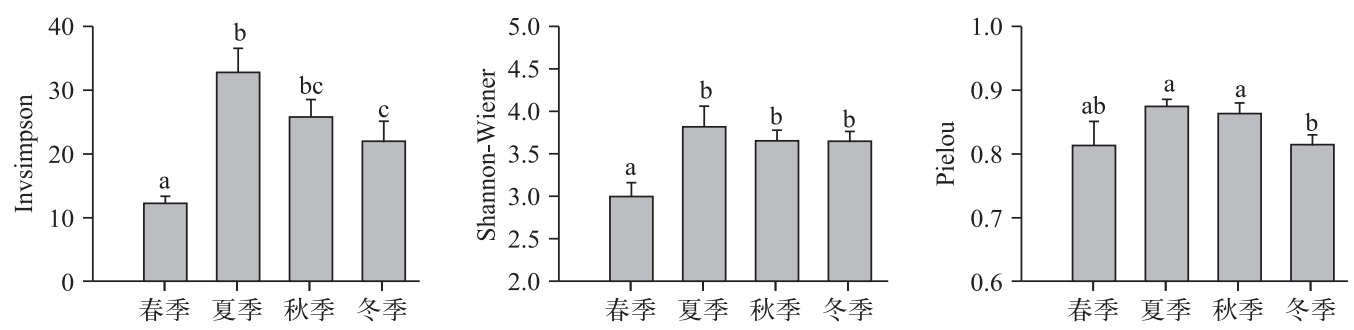

图 2 玄武湖 4 个季节浮游细菌群落 Alpha 多样性指数变化

Fig.2 Variations of the Alpha diversities of the bacterioplankton community in Xuanwu Lake in four seasons

离), 采用 NMDS 分析方法,绘制出样品的二维分布图 (图 3). 可以看出, 玄武湖不同季节的样品彼此重叠很 小, 这表明不同季节之间有比较显著的差异. 其中, 春季和冬季的样品点距离相对比较相近, 秋季和夏季的 点比较相近, 这表明春季、冬季样品中细菌群落组成比较相似, 夏季和秋季样品中细菌群落组成相对比较相 似. 从图中箭头可以看出, 箭头的指向不是一条直线, 从春季变化到夏季后有 “折返” 的现象, 通过秋季又到 达和春季相近的冬季, 从中可看出玄武湖中浮游细菌群落组成的季节性演替.

\section{4 浮游细菌群落结构与环境因子的关系}

由于本次研究数据趋势对应分析 (detrended correspondence analysis, DCA) 排序前 4 轴最大值为 3.02 , 介 于 3 4, 因此单峰模型和线性模型都适用 ${ }^{[23]}$. 应用 CCA 分析探究环境变量对浮游细菌群落的影响. 通过 vif.cca 函数计算每个环境变量的膨胀因子 ( variance inflation factors, VIF) 值 ${ }^{[24]}$ (分别为 $1.56 、 1.27 、 1.50$ 、 $6.51 、 5.60 、 2.73 、 2.40)$, 均小于 20 , 因此所有环境因子均保留. CCA 分析结果表明, 轴 1 和轴 2 分别解释了 $11.3 \%$ 和 7.9\% 的样本变异 (图 4). 为了检验每个环境因子对细菌群落结构影响的显著性, 使用 vegan 程序包 中的 envfit 函数进行分析. 结果 (表 2$)$ 表明, 温度、 $\mathrm{pH}$ 与排序轴有着非常显著的相关性 $(P<0.001), \mathrm{NH}_{4}^{+}-\mathrm{N}$ 和 $\mathrm{TP}$ 浓度与排序轴呈显著相关 $(P<0.05)$, 这说明温度是玄武湖年内浮游细菌群落结构的最主要影响因素, 其 次为 $\mathrm{pH}$.

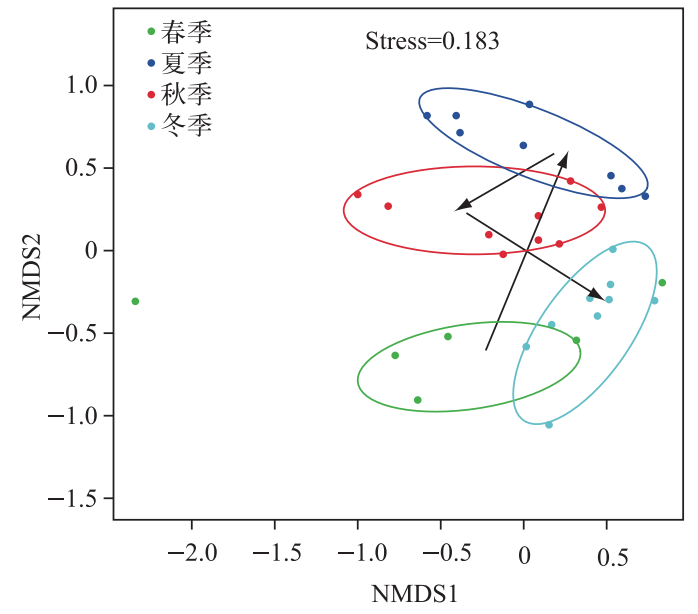

图 3 玄武湖浮游细菌群落结构的 NMDS 分析

Fig.3 Two-dimensional NMDS map of composition of bacterioplankton community structure in Xuanwu Lake

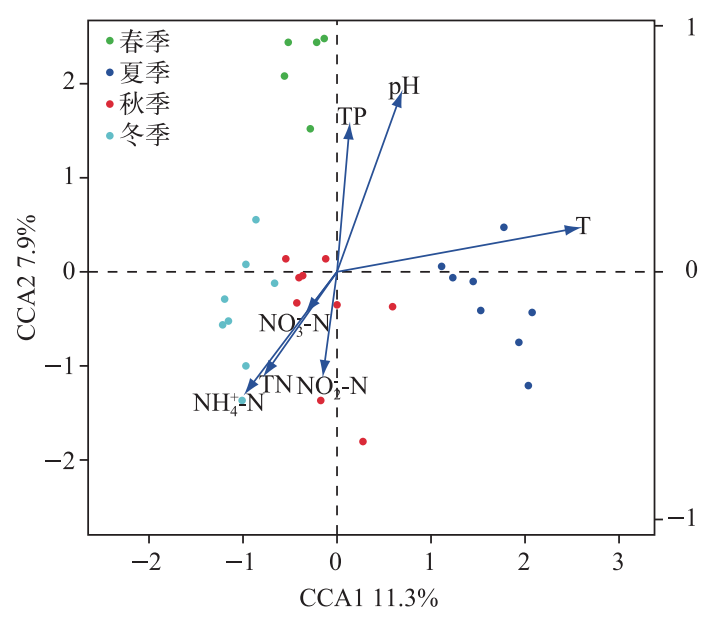

图 4 玄武湖样品浮游细菌群落与环境因子的 CCA 分析

Fig.4 CCA ordination biplot between sampling sites of Xuanwu Lake and environment factors

Mantel 及偏 Mantel 检验被用来分析样品间浮游细菌群落结构差异与环境变量差异的相关性. 样品间浮 游细菌群落结构的差异通过计算样品间 T-RFs 组成的 Bray-Curtis 距离所确定, 样品间环境变量的差异通过 
表 2 环境因子与 CCA 排序轴的相关性分析

Tab.2 Correlation analysis between CCA ordination axises and environmental factors

\begin{tabular}{clllrrrr}
\hline & $\mathrm{T}$ & $\mathrm{pH}$ & $\mathrm{TP}$ & $\mathrm{TN}$ & $\mathrm{NH}_{4}^{+}-\mathrm{N}$ & $\mathrm{NO}_{3}^{-}-\mathrm{N}$ & $\mathrm{NO}_{2}^{-}-\mathrm{N}$ \\
\hline $\mathrm{CCA} 1$ & 0.980 & 0.468 & 0.193 & -0.691 & -0.729 & -0.729 & -0.241 \\
$\mathrm{CCA} 2$ & 0.200 & 0.884 & 0.981 & -0.722 & -0.703 & -0.684 & -0.971 \\
$R^{2}$ & $0.895^{* * * 1)}$ & $0.417^{* * *}$ & $0.238^{*}$ & 0.215 & $0.296^{*}$ & 0.030 & 0.124 \\
\hline
\end{tabular}

1) 显著水平基于 1000 次置换; $* * *$ 表示 $P<0.001 ; * *$ 表示 $P<0.01 ; *$ 表示 $P<0.05$,下同.

计算环境因子的欧氏距离所确定. 偏 Mantel 检验就是在控制其他变量的情况下, 分别分析温度、pH 或营养 物质 (包括 $\mathrm{TP} 、 \mathrm{TN} 、 \mathrm{NH}_{4}^{+}-\mathrm{N} 、 \mathrm{NO}_{3}^{-}-\mathrm{N} 、 \mathrm{NO}_{2}^{-}-\mathrm{N}$ ) 与浮游细菌群落结构的关系. 从表 3 可以看出, 温度以及 $\mathrm{pH}$ 的差 异对于浮游细菌群落结构差异是显著相关的. 然而, 营养物质浓度的差异对浮游细菌群落结构差异无显著 相关性.

表 3 玄武湖样品微生物群落组成 ${ }^{1)}$ 和 环境变量的 Mantel 和偏 Mantel 检验

Tab.3 Mantel and partial Mantel tests for the correlations between the bacterioplankton community composition in sampling sites of Xuanwu Lake and environmental variables

\begin{tabular}{|c|c|c|c|}
\hline \multirow{2}{*}{ 影响 } & \multirow{2}{*}{$\frac{\text { Mantel 检验 }}{r}$} & \multicolumn{2}{|c|}{ 偏 Mantel 检验 } \\
\hline & & 控制 & $r$ \\
\hline 温度 & $0.523^{* * *}$ & $\begin{array}{c}\mathrm{pH} \\
\text { 营养物质 }\end{array}$ & $0.523^{* * *}$ \\
\hline $\mathrm{pH}$ & $0.227^{* * *}$ & $\begin{array}{c}\text { 温度 } \\
\text { 营养物质 }\end{array}$ & $0.227^{* *}$ \\
\hline 营养物质 & -0.137 & $\begin{array}{c}\text { 温度 } \\
\text { pH }\end{array}$ & -0.121 \\
\hline
\end{tabular}

为了定量分析不同类型的环境因子对于 微生物群落结构变异的影响作用大小, 对数据 进行了 VPA 分析. 结果 (图 5 ) 表明, $\mathrm{pH}$ 、温度 以及营养物质浓度分别单独解释了微生物群 落变异的 5.27\% ( $P<0.05) 、 16.37 \%(P<0.001)$ 和 $9.57 \%(P=0.621)$. 所有环境变量的解释量 为 $33.79 \%$.

\section{3 讨论}

本文通过 T-RFLP 技术研究了南京玄武湖 浮游细菌群落的季节性变化. Alpha 多样性指 数分析表明,不同季节玄武湖浮游细菌群落的 多样性是不同的. 夏季玄武湖的浮游细菌多样 性最高, 而春季最低. 邢鹏等 ${ }^{[25]}$ 、Wu 等 ${ }^{[26]}$ 对太

湖浮游细菌的研究也得出了类似的结论, 这可能是富营养化湖泊共有的特征. 研究表明, 浮游细菌与浮游藻 类的群落结构有着密切的相关性 ${ }^{[27-28]}$. 浮游藻类生物量也在夏、秋季达到一年的最大值, 浮游藻类分泌到胞 外以及细胞破裂产生的有机物是细菌分解作用的物质基础, 可能成为细菌营养物质的主要来源 ${ }^{[29]}$. 因此, 对于浮游细菌群落变化的研究可以在一定程度上反映浮游藻类群落变化.

多样性指数的季节变化说明玄武湖中细菌群落结构随着季节变化. NMDS 结果表明, 浮游细菌群落结 构从春季开始随着时间的推移到达和春季相差最大的夏季, 最终又回到和春季相近的冬季的结构. 这说明 随着环境因子变化到接近于最初始的状态, 细菌群落也能回到近似于初始状态时的结构. Deng 等 ${ }^{\left[{ }^{30]}\right.}$ 在研究 铀污染修复时发现随着环境的变化微生物的结构发生显著变化, 当一段时间后, 微生物群落结构能够恢复 到近似于变化前的状态. 这与我们的研究结果相一致.

进一步采用 CCA 分析探究导致玄武湖细菌群落产生这种季节性变化的原因. CCA 分析结果表明,温 度、pH 对群落结构有着极其重要的影响, 氮、磷等营养物质对细菌群落结构有一定影响, 但影响作用不如前 两者. 已有的研究表明, 微生物群落结构和多样性与空间 ${ }^{[31]}$ 、时间 ${ }^{[32-33]}$ 、环境变量 (如温度、 $\mathrm{pH}$ 和营养盐浓 度) 等因素有关 ${ }^{[34]}$. 因此, 根据环境因子的类型把环境变量划分成温度、pH 和营养物质(氮、磷等) 3 个组, 以 探究何种类型的环境因子对玄武湖浮游细菌群落结构的影响最大. Mantel 和偏 Mantel 检验结果表明, 温度 和 $\mathrm{pH}$ 对群落结构有着极其显著的影响 $(P<0.001)$. 但是, 营养盐对群落结构差异的影响并不显著. 有研究

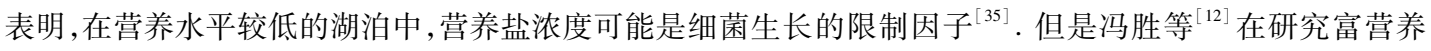
化湖泊一一太湖中发现营养物质并不是浮游细菌生长的主要限制因子, 本研究与其结论一致. 相反, 温度、 $\mathrm{pH}$ 能够显著影响浮游细菌群落结构. 温度直接影响着细菌的新陈代谢能力, 是细菌生长和存活最重要的影 
响因素之一, 随着温度的升高, 细胞中生物化 学反应的速率和生长速率都会加快,但温度 升高超过一定界限也会使机体的结构和功能 受到影响 ${ }^{[36]}$. 细菌生长同样需要一个合适的 酸碱环境, 不同类群的细菌有其最适宜的 $\mathrm{pH}$ 范围. Langenheder 等的研究发现: 在酸性的 湖泊中细菌生长被抑制 ${ }^{[37]}$, 表明不同 $\mathrm{pH}$ 对 细菌群落结构有一定的选择性. 在本研究中, 各采样站点属于弱碱性环境,适合大部分细 菌生长, 同时也存在一定的梯度, 因而会对浮 游细菌群落结构有一定的选择性.

VPA 分析表明,温度对于变异的解释量 最高. 营养盐虽然解释量达到了 $9.57 \%$, 但是 营养盐中包含了多个变量, 这是多个变量共 同作用的结果, 且影响并不显著 $(P=0.621)$. 此外,温度和 $\mathrm{pH}$ 共同解释的量仅为 $0.26 \%$,

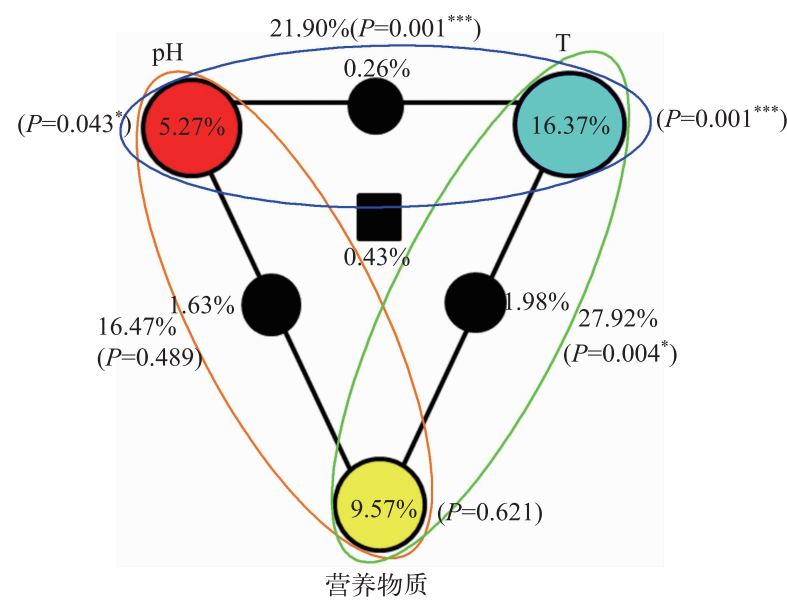

图 5 环境变量与玄武湖样品细菌群落的 VPA 分析

Fig.5 VPA analysis of bacterial communities in sampling sites of Xuanwu Lake and environmental variables 这说明温度和 $\mathrm{pH}$ 对浮游细菌群落的影响是 两个不同的方向,彼此之间干扰较小, 这与图 4 中 $\mathrm{pH}$ 和温度箭头方向接近正交的结果是一致的. 所有环境 变量的解释量为 $33.79 \%$, 说明还有其他一些没有检测的环境因子对浮游细菌群落结构起着重要作用.

与其他分子生物学技术相比, T-RFLP 技术具有较高的分辨率, 而且毛细管电泳装置一次可以检测多个 样品, 对于大范围长时间尺度的微生物群落结构分析研究具有较好的实用性. 但是, 由于基因组 DNA 提取、 PCR 扩增等实验过程中产生的偏倚性 ${ }^{[38-39]}$, T-RFLP 可能无法完全准确地反映环境样品中细菌群落的结构 和多样性. 同时,也有研究表明, 对不同物种的序列进行限制性酶切有可能得到相同的 T-RFs, 因此在 T-RFLP 的图谱上,一个峰代表的有可能不只是一个物种, 所以为了了解每个 T-RFs 所代表的物种, 还需要结 合克隆文库 ${ }^{[40-41]}$ 等方法进一步分析.

\section{4 参考文献}

[ 1 ] Zhao Dayong, Ma Ting, Zeng Jin et al. Study on eutrophication and heavy metal pollution of Xuanwu Lake. Journal of Hohai University (Natural Sciences)，2012, 40(1)：83-87. [赵大勇, 马婷, 曾巾等. 南京玄武湖富营养化及重金属污 染现状. 河海大学学报: 自然科学版, 2012, 40(1) : 83-87.]

[ 2 ] Mei Zhuohua, Zhang Zhehai, Zhao Chunxia et al. Dynamics of phytoplankton and water quality with control of Cyanobacteria bloom in Lake Xuanwu, Nanjing. J Lake Sci, 2010, 22(1) : 44-48. DOI: 10.18307/2010.0106. [梅卓华, 张哲海, 赵春霞等. 南京玄武湖蓝藻水华治理后水质和浮游植物的动态变化. 湖泊科学, 2010, 22(1): 44-48.]

[ 3 ] Sun Ying, Shu Tingting, Li Jing et al. Horizontal distribution characteristics of crustacean planktons and its relationship with environmental factors in Lake Xuanwu, Nanjing City. J Lake Sci, 2012, 24(3) : 422-428. DOI: 10.18307/2012. 0314. [孙颖, 舒婷婷, 李静等. 南京玄武湖浮游甲壳动物的水平分布及其与环境的关系. 湖泊科学, 2012,24 (3) : 422-428.]

[ 4 ] Newton RJ, Jones SE, Eiler A et al. A guide to the natural history of freshwater lake bacteria. Microbiol Mol Biol R, 2011, 75(1) : 14-49. DOI: 10.1128/MMBR.00028-10.

[ 5 ] De Figueiredo DR, Pereira MJ, Correia A. Seasonal modulation of bacterioplankton community at a temperate eutrophic shallow lake. World J Microb Biot, 2010, 26 (6) : 1067-1077. DOI: 10.1007/s11274-009-0272-3.

[ 6 ] Huang Yi, Shu Zhongya. Bacterioplankton Index of Biotic Integrity (BP-IBI) : An approach for assessing river ecosystem health in Dianchi watershed. Environmental Science, 2013, 34(8) : 3010-3018. [黄艺, 舒中亚. 基于浮游细菌生物完 整性指数的河流生态系统健康评价一一滇池流域为例. 环境科学, 2013, 34(8): 3010-3018.]

[ 7 ] Liu Lemian, Yang Jun, Yu Xiaoqing et al. Bacterioplankton diversity in Xiamen Houxi River Watershed along an urbanrural gradient and its relation to environmental factors. Chin J Appl Environ Biol, 2012, 18(4) : 591-598. DOI: 10.3724/ 
SP.J.1145.2012.00591. [刘乐冕, 杨军, 余小青等. 厦门后溪流域沿城乡梯度浮游细菌多样性及其与环境因子的 关系. 应用与环境生物学报, 2012, 18(4) : 591-598.]

[ 8 ] Sims A, Zhang Y, Gajaraj S et al. Toward the development of microbial indicators for wetland assessment. Water Res, 2013, 47(5) : 1711-1725. DOI: 10.1016/j.watres.2013.01.023.

[ 9 ] Jiang JG, Shen YF. Development of the microbial communities in Lake Donghu in relation to water quality. Environ Monit Assess, 2007, 127 (1) : 227-236. DOI: 10.1007/s10661-006-9275-9.

[ 10] Zeng J, Yang L, Du H et al. Bacterioplankton community structure in a eutrophic lake in relation to water chemistry. World J Microb Biot, 2009, 25( 5 ) : 763-772. DOI: 10.1007/s11274-008-9946-5.

[11] Liu Lanying, Lü Xin, Li Wei et al. Diversity of bacterioplankton community during winter and spring in the Lake Zuohai in Fuzhou. Acta Microbiologica Sinica, 2014, 54(2) : 200-210. [刘兰英, 吕新, 李巍等. 福州左海湖冬春季浮游细菌群 落 16S rRNA 多样性. 微生物学报, 2014, 54(2) : 200-210.]

[12] Feng Sheng, Gao Guang, Qin Boqiang et al. Variability of bacterioplankton in the north zone of Lake Taihu. J Lake Sci, 2006, 18(6) : 636-642. DOI: 10.18307/2006.0612. [冯胜, 高光, 秦伯强等.太湖北部湖区水体中浮游细菌的动态 变化. 湖泊科学, 2006, 18(6): 636-642.]

[13] Ni Yanyan, Zhang Jianying, Liang Luyi et al. Correlation analysis of water quality and the diversity of planktonic bacterial community in the wetland. Journal of Zhejiang University (Science Edition), 2014, 41(6) : 682-688. [倪燕燕, 张建英, 梁璐怡等. 湿地水质与水系浮游细菌多样性关联研究. 浙江大学学报: 理学版, 2014, 41(6): 682-688.]

[14] Liu WT, Marsh TL, Cheng H et al. Characterization of microbial diversity by determining terminal restriction fragment length polymorphisms of genes encoding 16S rRNA. Appl Environ Microbiol, 1997, 63(11) : 4516-4522.

[15] Marsh TL. Terminal Restriction Fragment Length Polymorphism (T-RFLP) : An emerging method for characterizing diversity among homologous populations of amplicons. Curr Opin Microbiol, 1999, 2(3) : 323-327. DOI: 10.1016/S1369-5274 (99) 80056-3.

[16] Kent AD, Smith DJ, Benson BJ et al. Web-based phylogenetic assignment tool for analysis of terminal restriction fragment length polymorphism profiles of microbial communities. Appl Environ Microbiol, 2003, 69(11): 6768-6776. DOI: 10. 1128/AEM.69.11.6768-6776.2003.

[17] Buchan A, Newell SY, Butler M et al. Dynamics of bacterial and fungal communities on decaying saltmarsh grass. Appl Environ Microbiol, 2003, 69(1) : 6676 - 6687. DOI: 10.1128/AEM.69.11.6676-6687.2003.

[18] Tom-Petersen A, Leser TD, Marsh TL et al. Effects of copper amendment on the bacterial community in agricultural soil analyzed by the T-RFLP technique. FEMS Microb Ecol, 2003, 46(1) : 53-62. DOI: http: //dx.doi.org/10.1016/S01686496( 03 )00192-2.

[19] Zhao Dayong, Sun Yimeng, Fang Chao et al. Vertical distribution of bacterial community composition in sediments of Meiliang Bay in Taihu Lake. Journal of Hohai University (Natural Sciences), 2013, 41(4) : 284-285. [赵大勇, 孙一萌, 方 超等. 太湖梅梁湾不同深度沉积物中细菌群落结构组成. 河海大学学报, 2013, 41(4): 284-285.]

[20] Chink J, Lueders T, Friedrich MW et al. Archaeal community structure and pathway of methane formation on rice roots. Microb Ecol, 2004, 47 (1) : 59-67. DOI: 10.1007/s00248-003-2014-7.

[21] Zeng J, Yang LY, Liang Y et al. Spatial distribution of bacterial communities in sediment of a eutrophic lake revealed by denaturing gradient gel electrophoresis and multivariate analysis. Can J Microbiol, 2008, 54(12) : 1053- 1063. DOI: 10. 1139/W08-098.

[22] Xie Weiping ed. Water quality inspection technology. Beijing: China Architecture \& Building Press, 2011: 136. [谢炜平. 水质检验技术. 北京: 中国建筑工业出版社, 2011: 136.]

[23] Lai Jiangshan, Mi Xiangcheng. Ordination analysis of ecological data using Vegan package in R. National symposium on the conservation and sustainable use of biodiversity, 2010. [赖江山, 米湘成. 基于 Vegan 软件包的生态学数据排序分 析. 全国生物多样性保护与持续利用研讨会, 2010.]

[24] Groß J. Variance inflation factors. R News, 2003, 3(1) : 13-15.

[25] Xing Peng, Kong Fanxiang, Gao Guang. Phylogenetic diversity and seasonal variation of bacterioplankton communities in Lake Taihu. J Lake Sci, 2007, 19(4) : 373-381. DOI : 10.18307/2007.0404. [邢鹏, 孔繁翔, 高光. 太湖浮游细菌种 群基因多样性及其季节变化规律. 湖泊科学, 2007, 19(4): 373-381.]

[26] Wu QL, Chen YW, Xu KD et al. Intra-habitat heterogeneity of microbial food web structure under the regime of eutrophi- 
cation and sediment resuspension in the large subtrophical shallow lake Taihu, China. Hydrobiologia, 2007, 581: 241254. DOI: $10.1007 / \mathrm{s} 10750-006-0500-x$.

[27] Lindström ES. Investigating influential factors on bacterioplankton community composition: Results from a field study of five mesotrophic lakes. Microbial Ecol, 2001, 42(4) : 598-605. DOI: 10.1007/s00248-001-0031-y.

[28] Vieira RP, Gonzalez AM, Cardoso AM et al. Relationships between bacterial diversity and environmental variables in a tropical marine environment, Rio de Janeiro. Environ Microbiol, 2008, 10(1) : 189-199. DOI: 10.1111/j. 1462-2920. 2007.01443.x.

[29] Jensen LM. Phytoplankton release of extracellular organic carbon, molecular weight composition, and bacterial assimilation. Mar Ecol Prog Ser, 1983, 11(1) : 39-48. DOI: 10.3354/meps011039.

[30] Deng Y, Zhang P, Qin Y et al. Network succession reveals the importance of competition in response to emulsified vegetable oil amendment for uranium bioremediation. Environ Microbiol, 2015. DOI: 10.1111/1462-2920.12981.

[31] Fortunato CS, Herfort L, Zuber P et al. Spatial variability overwhelms seasonal patterns in bacterioplankton communities across a river to ocean gradient. ISME J, 2012, 6(3) : 554-563. DOI: 10.1038/ismej.2011.135.

[32] Crump BC, Kling GW, Bahr M et al. Bacterioplankton community shifts in an arctic lake correlate with seasonal changes in organic matter source. Appl Environ Microbiol, 2003, 69(4) : 2253-2268. DOI: 10.1128/AEM.69.4.2253-2268.2003.

[33] Kent AD, Yannarell AC, Rusak JA et al. Synchrony in aquatic microbial community dynamics. ISME J, 2007, 1( 1) : 3847. DOI: $10.1038 /$ ismej.2007.6.

[34] Nelson CE. Phenology of high-elevation pelagic bacteria: The roles of meteorologic variability, catchment inputs and thermal stratification in structuring communities. ISME J, 2009, 3(1) : 13-30. DOI: 10.1038/ismej.2008.81.

[35] Chrzanowski TH, Sterner RW, Elser JJ. Nutrient enrichment and nutrient regeneration stimulate bacterioplankton growth. Microbial Ecol, 1995, 29(3) : 221-230. DOI: 10.1007/BF00164886.

[36] Yannarell AC, Triplett EW. Geographic and environmental sources of variation in lake bacterial community composition. Appl Environ Microbiol, 2005, 71(1) : 227-239. DOI: 10.1128/AEM.71.1.227-239.2005.

[37] Langenheder S, Lindström ES, Tranvik LJ. Weak coupling between community composition and functioning of aquatic bacteria. Limnol Oceanogr, 2005, 50(3) : 957-967. DOI: 10.4319/lo.2005.50.3.0957.

[38 ] Head IM, Saunders JR, Pickup RW. Microbial evolution, diversity, and ecology: A decade of ribosomal RNA analysis of uncultivated microorganisms. Microbial Ecol, 1998, 35(1) : 1-21. DOI: 10.1007/s002489900056.

[39] Rocker A, Burr M, Camper AK. Genotypic microbial community profiling: A critical technical review. Microbial Ecol, 2007, 54(2) : 276-289. DOI: 10.1007/s00248-006-9199-5.

[40] Gonzalez JM, Simo R, Massana R et al. Bacterial community structure associated with a dimethylsulfoniopropionate-producing North Atlantic algal bloom. Appl Environ Microbiol, 2000, 66(10) : 4237-4246.

[41] Derakshani M, Lukow T, Liesack W. Novel bacterial lineages at the (sub) division level as detected by signature nucleotide-targeted recovery of $16 \mathrm{~S}$ rRNA genes from bulk soil and rice roots of flooded rice microcosms. Appl Environ Microbiol, 2001, 67 (2) : 623-631. DOI: 10.1128/AEM.67.2.623-631.2001. 